\begin{tabular}{|l|l|l}
\hline & $\begin{array}{c}\text { Informing Science: } \\
\text { the International Journal of } \\
\text { an Emerging Transdiscipline }\end{array}$ & $\begin{array}{l}\text { An Official Publication } \\
\text { of the Informing Science Institute } \\
\text { InformingScience.org }\end{array}$ \\
\hline
\end{tabular}

Volume 20, 2017

\title{
CO-DEVELOPMENT OF A WIKI FOR TRACKING THE ENVIRONMENTAL FOOTPRINT OF SMALL BUSINESS ACTIVITIES
}

\begin{tabular}{lll}
\hline Helen Hasan * & University of Wollongong, Wollongong, & $\underline{\text { hasan@,uow.edu.au }}$ \\
& NSW, Australia & \\
Corina Ionescu & University of Wollongong, Wollongong, & $\underline{\text { corina@,uow.edu.au }}$ \\
& NSW, Australia & \\
$*$ Corresponding author & &
\end{tabular}

\begin{abstract}
Aim/Purpose Climate change mitigation is a global challenge, in which academia and business have a role to play. This research explores ways to develop a freely-available information system that would enable small businesses to identify and reduce their environmental footprint.

Background While large organizations have the resources to track emissions and other pertinent data, small businesses may not, despite intentions to be more environmentally responsible. Freely available applications to track emissions focus on the carbon footprint of things, whereas activities are a more meaningful unit of analysis for business managers.

Methodology Using a design science research approach, we conducted a study of a collaborative project that investigated how a low-cost, freely-available online wiki could be developed by group of students, under the guidance of university scholars and business owners. In the project, different student groups were tasked to create the wiki, input content and design a dashboard interface for managers to find data relevant to their business. The research takes an information systems view of the project, relying on the holistic notion of activity from activity theory and taking a design science approach to the study.

Contribution The paper contributes to the practices of green information systems, climate change, and small business. Theoretically it provides new insights into the linear view of design science in resource poor, collaborative projects.
\end{abstract}

Accepting Editor Raafat Saadé | Received: June 25, 2017| Revised: September 28, 2017 | Accepted: October 6, 2017.

Cite as: Hasan, H., \& Ionescu, C. (2017). Co-development of a wiki for tracking the environmental footprint of small business activities. Informing Science: the International Journal of an Emerging Transdiscipline, 20, 237-258. Retrieved from http://www.informingscience.org/Publications/3874

(CC BY-NC 4.0) This article is licensed to you under a Creative Commons Attribution-NonCommercial 4.0 International License. When you copy and redistribute this paper in full or in part, you need to provide proper attribution to it to ensure that others can later locate this work (and to ensure that others do not accuse you of plagiarism). You may (and we encourage you to) adapt, remix, transform, and build upon the material for any non-commercial purposes. This license does not permit you to use this material for commercial purposes. 
Wiki for Tracking the Environmental Footprint

Findings

Recommendations for Practitioners

Recommendation for Researchers Impact on Society

Future Research
The research demonstrates the viability of an online system to track the environmental footprint of business activities. It reveals the challenges from a design science perspective of attempts to create online systems using freely available products and labor.

Meaningful information systems to assist small businesses to manage their environmental footprint should focus on activities not things, be low cost and easy to use.

Complex nonlinear design science frameworks may be needed to build community-based green information systems projects.

This paper examines the role that university-community partnerships can play in mitigating climate change.

We should now investigate ways to ensure the viability and sustainability of systems developed by groups of university students.

Keywords climate change, small business, wiki, activity theory, design science, green information systems

\section{INTRODUCTION}

As a significant global challenge of our time, climate change mitigation is concerned with issues such as the reduction of greenhouse gases (GHG), energy efficiency, recycling, and technology innovation (Aldy, Krupnick, Newell, Parry, \& Pizer, 2010). Human activities, including those of most businesses, are contributing to climate change so that, in order to be globally successful, efforts to mitigate climate change requires efforts by all businesses to reduce their environmental footprint (Pachauri \& Reisinger, 2007). This footprint can be the result of many factors including their direct emissions of GHG and other pollutants as well as indirect emissions of GHG from their suppliers and customers, i.e., up and down their supply chain (Chali, 2013; Tekin, Ertürk, \& Tozan, 2015).

Researchers and practitioners from many disciplines, including the informing sciences, are addressing climate change problems, recognizing that these problems are complex and transdisciplinary (Mauser et al 2013). According to Kuechler and Vaishnavi (2011) the informing science literature endorses the view that such "relevant business problems are simply too complex to yield to the academic tendency to decomposition" (Kuechler \& Vaishnavi, 2011, p. 126). To deal with this complexity, information systems (IS) researchers use inductive holistic approaches such as those using action research to cocreate systems for climate change mitigation and adaptation (see, e.g., Hasan, Smith, \& Finnegan, 2017). The research presented in this paper forms a major part of a wider project which aims to cocreate such a system.

In many countries, companies are required to report on their GHG emissions and make steps to reduce them. In Australia, the government's Clean Energy Regulator has oversight for this and the Emissions and Energy Reporting System (EERS) is responsible for all reporting under the National Greenhouse and Energy Reporting Act 2007 (NGER Act) (Australian Government, 2007). Although the NGER Act requires only large businesses to collect data and report on GHG emissions, there is concern among small businesses that they may, in the future, be required to do so. Representatives of small businesses, who took part in our research, were conflicted by this. On the one hand they would certainly not have the know-how, or could afford the expertise, to collect this sort of data. On the other hand, as global citizens, many are concerned about the impact of their business on the environment and would like to be able to look for ways to reduce their environmental footprint (Walsham, 2012).

The research reported in this paper attempts to reconcile this dilemma. The project we describe began late in 2008 with a day-long workshop organized around presentations of current relevant work by researchers in various disciplines at a regional university. Workshop participants ranged from professors to undergraduate students together with representative from local businesses who brought 
with them some real-world challenges concerned reducing their environmental footprint. Partnerships between universities and local communities, involving small business with information and communications technologies (ICT), can be a suitable vehicle for sustainable development (Onojaefe \& Leaning 2007). The challenge that local businesses posed to the university's researchers was to create an affordable way for a small business to estimate the environmental footprint of their various business activities.

The university scholars' response to the challenge was a transdisciplinary Carbon Wiki project which would be undertaken as series of student assignments, supervised by researchers and practitioners with expertise in environmental studies, small business, computer science, and IS. With no funding, they would rely on their own expertise and contacts, use freely available tools, and set suitable tasks as student assignments. They would also rely on citizens to populate the wiki encouraged by examples of citizen-based environmental monitoring reported by others (see, e.g., Strorer, Chao, Torelli, \& Ostrowski, 2016).

Over the ensuing seven years (2010-2016), different groups of computer science students undertook assignments in their annual final year capstone unit. These assignments were designed to (1) create the wiki to store data, (2) to develop input forms for the wiki, (3) to populate the wiki by crowdsourcing, and (4) to design a user-friendly dashboard interface for managers to find data relevant to their business. Reports and artifacts produced by previous year's students were to be made available to subsequent groups who added to the Carbon Wiki produced by the first group of students in 2010.

In late 2010, a post-graduate IS research student in the field of Green Information Systems (Green IS) proposed that her research would examine the outcomes of all the group assignments of all the computer science students and conduct an investigation of the whole project as both a theoretical and practical endeavor. This paper concerns this study, which was completed in 2016. The literature review, methodology, and results are presented in this paper.

Green IS scholars have expertise in the way ICT can provide powerful tools for collecting data that can be processed into information for monitoring and predicting emissions (Elliot, 2011; Melville, 2010; Watson, Boudreau, \& Chen, 2010). Many of these tools are now freely available on the Internet, predominantly in the form of so called Carbon Calculators that enable the user to determine the Carbon Footprint of things, such as equipment and chemicals. To business managers, things are only of interest in their ability to enable effective business activities that deliver products and services to customers. We thus refer to the concept of activity, as understood in activity theory, to underpin the research in order to allow both theoretical and practical outcomes.

This study presented here has both practical and theoretical contributions. For practical outcomes, we look for ways to create freely available, easy to use tools that enable small businesses to determine the contributions to the environmental footprint of their business activities, such as producing goods and running an office. The particular design challenge was how to develop a significant societal information system to be used for the public good at low cost and no budget. This research produced the robust design for the desired system and some unexpected findings that contribute extensions to the traditional design science research (DSR) framework.

\section{BACKGROUND}

To set the context for this research, we summarize the input from the various disciplines represented. These include the following: environmental and Green IS issues that motivate the project; the relevant characteristics of small businesses; wikis as public knowledge repositories; the challenges of developing systems with freely available ICT and student labor; and the suitability of IS and informing sciences concepts to underpin the research. The theoretical lens of activity theory is also introduced. 


\section{THE ENVIRONMENTAL IMPERATIVE}

This research is motivated by concern for the environment and the responsibility of the research, in many disciplines, to assist with global efforts of sustainable development. Efforts to lower our environmental footprint are driven by public debate on climate change and the responsibility of governments, business, and community to mitigate the harmful effects of GHG emissions from human activities. Building a sustainable, environmentally-responsible civilization should be one of the main elements of the future vision of governments, businesses, NGOs, and communities. However, the problem is complex and there have been many efforts to address the problem at a global level driven by the United Nations (UN) and others with limited success.

The World Conservation Strategy was created in 1980 combining the International Union for the Conservation of Nature and Natural Resources (IUCN), the UN Environmental Program (UNEP) and the World Wildlife Fund (WWF). Three years later, in 1983, a new organization, the World Commission on Environment and Development (WCED), was formed independent of the UN and is informally known as the Brundtland Commission. The mission of the WCED was to unite countries with the aim of sharing environmental problems and solutions in order to develop a sustainable future. In 1988 the United Nations Environmental Program (UNEP) and World Meteorological Organization (WMO) decided to establish a leading inter-governmental body for assessing the research on climate change called the Intergovernmental Panel on Climate Change (IPCC) http://ipcc.ch/organization/organization.shtml). From that point there was unprecedented global attention on the consequences of human activities on the environment.

The Brundtland Commission report (World Commission on Environment and Development [WCED], 1987) emphasized the critical importance of two interconnected entities, "environment" and "development", and the vital relationship between them. The environment cannot be looked at as a "sphere" that exists separate from "human emotions and action" while development cannot be strictly seen as a "term habitually used to describe political goals or economic progress". Rather, it should be understood that the two have an ecological interconnection, and that there is a significant relationship between sustainable development and climate change, and this has been the focus of many initiatives of the UN. The Brundtland report "Our Common Future" contains the much quoted definition that rings true to most people, namely that "sustainable development is the kind of development that meets the needs of the present without compromising the ability of future generations to meet their own needs".

This global concern was reflected in our local community at the time our project began. The Australian government had ratified their commitment to the Kyoto agreement and introduced the NGER initiative to encourage businesses to lower their Scope 1 (direct) and Scope 2 (indirect) GHG emissions. It did not however address issues of polluting waste and emissions from non GHG sources and so does not cover the whole spectrum of a business's environmental footprint. Neither does it require any reporting on the emissions from small businesses that make up the majority of Australian business. Our project ventures into these areas.

\section{GREEN INFORMATION SYSTEMS}

This research is aligned with the current message of a new field of Green IS, which proposes that information systems (IS) can be a powerful tool in supporting businesses to improve their environmental footprint (Watson, 2007). One of the ways to do this is by providing information and the tools to manipulate information to monitor and predict (Elliot, 2011; Melville, 2010; Watson et al. 2010). Researchers such as Howard, Lubbe, and Klopper (2015) and Hasan et al. (2017) continue to investigate and promote the relationship between Green IS and environmental sustainability.

In the last half century, IS has been one of the greatest forces in improving productivity through the application of ICT (Avital et. al, 2007). However, globally 5-7 \% of the GHG emissions are estimated to come from ICT and in Australia, where this project took place, the ICT industry is responsible 
for consumption of more than 7\% of all electricity generated (Philipson, 2010). To balance this, there are now program where IS with ICT can be used to reduce emissions (Watson et al., 2010) and innovatively enhance sustainable business practice (Melville, 2010; Seidel, Recker, \& vom Brocke, 2013). The climate change challenge is addressed in the both Green ICT (the greening of ICT) (see Chen, Boudreau, \& Watson, 2008; CFO, 2009; Molla et al., 2009; Rowsell-Jones \& Mingay, 2008) and Green IS (the greening by ICT) (summarized by Malhotra, Melville, \& Watson, 2013). According to Watson et al. (2010), Green IS represents the larger of these two streams and its focus is on study of design, implementation, and impact of IS within the business in support of all environmental initiatives.

\section{CHARACTERISTICS OF SMALL BUSINESSES}

It is clear that businesses cannot stop operating just because they have an environmental footprint. However, changing entrenched environmentally damaging ways of working can be difficult and expensive. Small businesses, in particular, cannot afford the extra cost involved in changing to more environmentally sustainable ways of operating even if they knew how best to do this (Bos-Brouwers, 2010). They often do not have the resources to investigate ways to assess and track their environmental footprint in order to find ways to reduce it. Yet, they often want to undertake this task for several reasons including the prospect of changes in legislation that could require this, well-known benefits to the image of the business of having a green image, and the personal desires of managers to do the right things with respect to the environment. Small businesses are not just little big businesses and, in Table 1, Bos-Brouwers (2010) summarizes the distinguishing characteristics of small businesses that we needed to take into account when undertaking our design.

We recognized these characteristics in the managers of local small businesses who participated in our initial workshop. When speaking about their businesses, they referred to their operations in terms of processes and activities rather than the specific equipment they used. So when talking about their environmental footprint, an early decision was made to make activity our unit of analysis when designing our green information system. Also, in dealing with their resource poverty, the decision was made to use open source software platforms and student final year assignments for labor under the guidance of volunteers from small local IT firms.

Table 1.Characteristics of Small Businesses against those of Large Companies (Bos-Brouwers 2010).

\begin{tabular}{|l|l|}
\hline SMALL BUSINESS & LARGE COMPANY \\
\hline $\begin{array}{l}\text { Dominant role of the entrepreneur/owner with focus } \\
\text { on the operational activities }\end{array}$ & $\begin{array}{l}\text { Delegated management control between board of } \\
\text { directors and shareholders }\end{array}$ \\
\hline $\begin{array}{l}\text { Resource poverty (capital, time, knowledge and skilled } \\
\text { personnel) }\end{array}$ & Economy at scale, resource abundance \\
\hline Flexible organization capacities & Bureaucratic rigidity \\
\hline Focus on short term & Focus on mid-to-long term \\
\hline $\begin{array}{l}\text { Strong local/regional focus and customer needs orienta- } \\
\text { tion }\end{array}$ & $\begin{array}{l}\text { Strong (inter)national focus and looser ties with } \\
\text { customers }\end{array}$ \\
\hline Low degree of formalization & High degree of formalization \\
\hline
\end{tabular}

\section{WIKIS AS OPEN INFORMING SYSTEMS}

There are many open source platforms available for our purpose. The choice of free technological systems that would be used by this project was left to the computer scientists and their students. The first freely available applications that were examined as possibly useful to the project were the many carbon calculators that were found on the internet. However these were almost all associated with things such as equipment, machines, and vehicles and not the activities that we had decided were a more meaningful unit of analysis for small businesses. 
At the time the project started, wikis had a growing reputation on the open Internet for producing evolving stores of shared knowledge and take advantage of the collaborative efforts of people to create an effective knowledge repository (Meloche, Hasan, Willis, Pfaff, \& Qi, 2009). In comparison with traditional informing systems, wikis enable people to work together more efficiently and flexibly (Regolini. Berger, Jannès-Ober, \& Dorren, 2008). Technically, a wiki is a collection of web pages with cross links between internal pages where each page can be edited, keeping a complete record of such changes. It is basically an open author system for a conjoined construction and maintenance of websites (Fuchs-Kittowsk \& Köhler, 2002). A wiki thus becomes an evolving knowledge repository where users are encouraged to make additions to this repository by adding new documents or working on existing ones (Hasan \& Pfaff, 2006). It distributes ownership, and responsibility for, the store of information to all those who have access to it.

Whether using a wiki or more conventional data storage there is still a need to provide mechanisms for inputting data and outputting information. For inputs it was necessary to create wiki forms and we chose a dashboard interface for wiki content to be accessed by the small business end-users.

As an easy to use type of computer interface, dashboards are a common end-user interface in today's world of web-based applications. The design of a dashboard is inspired by the automobile's dashboard, because of the easy- to-read organized information. A computer dashboard is designed as "a set of menus and interfaces that give the user quick access to data and information as well as simplify any editing processes they might need for a website or even an application"

(http://www.designyourway.net/blog/?s=dashboard). Most dashboard use interactive Graphical User Interfaces (GUI) and employ the metaphor of the dashboard for ease of use it offers the endusers. There are many low cost tools for implementing such interfaces (https://smallbiztrends.com/2015/03/best-business-dashboard-apps.html).

\section{FREE RESOURCES: STUDENT DEVELOPMENT AND CROWDSOURCING}

To build an open system for resource poor small business, we relied on free student labor and free crowdsourced content for the wiki. Constructive team projects provide students with the opportunity to integrate all the skills and knowledge learnt from their previous studies into real practice (Guo, 2004). Realistic student assignments can also result in outcomes that are of practical use to communities and small business that could otherwise not afford them.

Most university computer science and information systems students are required to undertake final year team projects often done as local industry placements (see, e.g.,

https://www.computer.org/cms/Computer.org/professional-

education/curricula/ComputerEngineeringCurricula2016.pdf). Supported by abundant research, such curricula recognize the benefits of such programs for students and their future job prospects. There is little research to show the contribution that these students make to the industry partner, although the willingness of firms to participate, suggests that some value is added. Bramwell and Wolfe (2008) describe circumstances where student placements result in beneficial knowledge transfer from students to local business leading to regional economic development. Our students were motived by the desire for a good grade but also volunteered for the project because of their concern for the environment so we had reason to believe that they would make every effort to produce good outcome in their allotted task. However, as noted by Van Gorp (2014), project involving diverse groups of volunteers can have communication and coordination challenges, issue of variable quality, and difficulties in working across different cultures.

Another challenge for the project was to populate the Carbon Wiki with suitable data at little cost or effort. Crowdsourcing was an obvious solution. Majchrzak and Malhotra (2013, p. 258) adopt the definition of crowdsourcing as: "a type of participative online activity in which an individual, an institution, a non-profit organization, or company proposes to a group of individuals of varying knowledge, heterogeneity, and number, via a flexible open call, the voluntary undertaking of a task." 
Crowdsourcing can be a tool for informing as it provides a means to allow meaningful public input into an open knowledge repository in areas of significant science and technology concern (PytlikZil$\operatorname{lig} \&$ Tomkins, 2011). Our focus on business activities is quite novel, so that few observations of environmental footprint of such activities currently exist. This makes it an idea topic for crowdsourcing, which has the potential to overcome issues related to spatial and temporal representativeness of observations. (Muller et al., 2015). These authors do however warn of challenges in enticing people to contribute to crowdsourcing efforts, although a topic such as climate change is popular among those who want to add value to science, technology, and society. Muller et al. (2015, p. 12) note that "arguably the biggest challenge in incorporating crowdsourced data in the atmospheric sciences - as for other disciplines - is overcoming the barriers associated with utilizing a non-traditional source of data, i.e. calibration and other quality assurance/quality control (QA/QC) issues"

\section{INFORMATION SYSTEMS AND INFORMING SCIENCE}

This project lies at the intersection of the fields of information systems and informing science. Among the many definitions of information systems, Avison and Elliot, (2006) suggest that "the study of information systems and their development is a multi-disciplinary subject and addresses the range of strategic, managerial and operational activities involved in the gathering, processing, storing, distributing and use of information, and its associated technologies, in society and organizations" These author go on to quote Alan Lee to say that what distinguish information systems from other disciplines is that it "examines more than just the techno logical system, or just the social system, or even the two side by side; in addition it investigates the phenomena that emerge when the two interact". Wood Harper (2011) notes that the information systems scholars take ideas from much older disciplines, in particular ideas from general systems theory, human activity and behavior, sociotechnical systems, structured systems analysis, data analysis, and technical specification. Baskerville and Myers (2002) believe that the field of information systems has now matured to the point that it can be a reference discipline itself, for example for the field of informing science.

Informing science (www.informingscience.org) is the transdisciplinary quest to discover better ways to inform. Cohen (2009) mentions other reference disciplines including psychology, computer science, evolutionary biology, and linguistics. As Cohen (2009, p. 1) observes "in recent decades, advances in information technologies magnify the impact and importance of this transdiscipline". With the latest social media, "people are no longer simply consumers of data, they can also be producers" (Muller et al., 2015). This expands the whole notion of informing and extends the application of informing science as a transdisciplinary field of study.

Both informing science and IS have grown with the advent of digital technologies. Their broad scope covers the issues, purpose, and challenges of the project described in this paper.

\section{THEORETICAL LENS}

Because it was found appropriate to focus on the environmental footprint of business activities, the study takes activity as the unit of analysis as informed by activity theory. Activity theory takes a holistic perspective on how tools mediate what people do and how peoples' subjective interpretation of work leads to new tools and learning (Leontiev, 1981; Vygotsky, 1978). It prioritizes the purpose of an activity over tools which can be changed or replaced. Based on the idea that human activity is mediated by cultural signs, words, and tools, activity, in the Activity Theory sense, is an imperfect translation of the Russian word deyatelnost which carries the connotation "doing in order to transform something" (Kuuti, 1995, p. 23). Engeström (1987) introduced the concept of a "collective activity system" such as, in our case, a small business and the notion that learning occurs through contradictions within and between such activity systems. An implicit assumption about an activity is that, despite awareness of the agreed purpose of a collective activity, the actual outcomes of that activity often differ from those anticipated. Our use of activity theory reflects the work of Singh, Hawkins, and 
Wiki for Tracking the Environmental Footprint

Whymark (2007) who employed the theory for a study of collaborative knowledge building as a group activity.

\section{METHODOLOGY}

The research presented in this paper is the contribution of an IS DSR study to the project described above and has the potential to provide both theoretical and practical outcomes. The key requirements for practice were that the system produced should be easy to use and freely available to small businesses. The theoretical outcome emerged as a contribution to the area of IS DSR. The research methodology chosen for this project was strongly influenced by these requirements and will now be described.

As the aim of the project was to design an IS artifact in the form of a wiki repository and a dashboard interface, a constructivist paradigm was adopted. The research design was formed around the availability of students who were required to undertake group or individual projects as part of their courses. As will be explained below, a design science approach was used to provide a framework that allowed for a contribution towards the theoretical component of the research. This follows the example of Drechsler (2015) who advocates DSR when seeking to bridge the theory-practice gap for a practitioner audience.

The nature of the research problem described above and the decision to focus on business activities indicated that activity theory would be used to guide the research and its interpretation. The concept of activity was used as a holistic unit of analysis in identifying those activities of small business that have a significant environmental footprint, such as space heating and cooling, manufacturing products, and transportation. The conduct of this study follow the steps of design science (Peffers, Tuunanen, Rothenberger, \& Chatterjee, 2007) and the outcomes provide new understandings of the DSR paradigm where evaluation of the artifact provides a better understanding of the problem in order to improve both the quality of the product and the research findings (Walls, Widmeyer, \& El Sawy, 1992).

\section{RESEARCH APPROACH}

The adoption of a DSR approach to the research is justified as follows. Peffers et al. (2007, p. 55), observe that "whereas natural sciences and social sciences try to understand reality, DSR attempts to create things that serve human purposes." The fundamental principle of DSR is that knowledge and understanding of a design problem and its solution are acquired in the building and application of an artifact (Hevner, March, Park, \& Ram, 2004). However, DSR is an IS research paradigm where an important dichotomy must be faced. Design is both a process (a set of activities, a verb) and a product (an artifact, a noun) and the designed artifacts are both useful and fundamental in understanding that problem (Walls et al., 1992). This view of design supports a problem-solving paradigm that continuously shifts perspective between design processes and designed artifacts to solve complex problems (Gregor \& Hevner, 2013). The design process is a sequence of expert activities that produces an innovative product (i.e., the designed artifact). The result artifact can be a technical tool evaluated ex post or the design of a system evaluated ex ante, i.e., prior to artifact construction (Venable, PriesHeje, \& Baskerville, 2012)

The focus on both theoretical and practical outcomes in the design and development of artifacts is akin to an action research paradigm which allows inquiry, explaining social situations, through informed interventions and "is problem-focused, context specific and future-orientated" (Waterman, Tillen, Dickson, \& De Koning, 2001, p. 4). Action research develops a solution to a practical problem that is of value to the people with whom the researchers are working, while at the same time developing theoretical knowledge of value to a research community (Coghlan \& Brannick, 2014; Kock, McQueen, \& John, 1997). All team members recognized the dual imperatives of theory and practice to meet objectives of both the problem solving interest cycle and research interest cycle (McKay \& 
Marshall 2001) as researchers and practitioners worked conjointly towards both research and practical outcomes.

In our case, the project research participants initially engaged with practitioners in a day-long workshop in 2008 involving researchers and students from the university together with local small businesses owners. Of the 50 attendees at the workshop, we arranged to have approximately equal numbers of each of the three groups, researchers, students, and business people, with as much discipline diversity as possible. The university research unit, which sponsored the workshop, has for many years held weekly open meetings and continues to do this. Participants in the project agreed to attend these once a month to discuss progress. Eleven, of the original workshop group, have continued to attend, including 2 local IT consultants and 2 managers of local "green" businesses. 3 computer scientists, 2 information systems, and 1 environmental science researchers together with the IS research student whose study is the focus of this paper. Apart from this IS research student, the computer science student cohort involved in the project has changed over the years.

The 2008 workshop established the need to develop a system for small businesses to be able easily to track their environmental footprint. The business managers at the workshop insisted that the system would have to be freely available, easy to use, and focus on typical business activities. This was the start of the Carbon Wiki project using the expertise of participants from the university and local small businesses. The IS DRS component presented in this paper, a study conducted from 2010 to 2016, contributes a framework of design science incorporating the notion of activity as understood by activity theory.

\section{RESEARCH DESIGN OF THE IS DSR STUDY}

Throughout 2009, monthly meetings discussed how the project could work and what resources were available. One of the local IT consultants advocated the use of MediaWiki (www.mediawiki.org/wiki/MediaWiki) the open-source engine of Wikipedia. He volunteered to act as an advisor to a student group who could do the initial installation in 2010. The Computer Science Department of the university would provide a server that would give public access.

By the end of 2009, the project team had devised a sequence of tasks that could be carried out by computer science students in the team project required for their final undergraduate year. Only groups who had a passionate interest in environmental issues would be chosen. Five systems development activities were carried out by student groups as follows:

1. Computer science students would install an open source version of MediaWiki on a server at the university that allowed public access. This artifact would be called the Carbon Wiki. This installation was successfully completed in 2010 and demonstrated for evaluation at the last project meeting that year.

2. A second group of computer science students would design input forms to the Carbon Wiki where contributors could enter any data in the form of estimates of the emissions from business activities carried out under circumstance with which they were familiar and which they would describe. Forms were created by a student group in 2011. The local IT advisor evaluated these, reporting that they were operational and could be used by the following year's students.

3. Crowdsourcing would be used to populate the wiki led by a third group of students in 2012. The voluntary aspect of crowdsourcing was a challenge for the students and unfortunately the wiki was not well populated with realistic data. For much of the year the server used for the project was closed down and the students could have access only to a local version of the Carbon Wiki. To complete their course, they asked other students and friends to enter items into the wiki that were invented to provide some content for the next year's students.

4. A dashboard interface was to be built by the fourth group of computer science students in 2013 to allow business managers to access relevant data from the wiki from which they could deter- 
mine the environmental footprint of all their business activities. However, no student group volunteered to do the project.

5. In parallel with phases 1-4 a postgraduate IS student would conduct a requirements analysis, create a data structure, design and develop the requirements for the dashboard interface suitable for the needs of small businesses end-users.

The research presented in this paper is that of the fifth phase of the project, i.e., the study conducted by an IS post-graduate student. This the most comprehensive phase of the whole project as it integrates all other phases. In late 2010, this post-graduate IS student was enrolled, part-time, in a masters by research degree in the field of Green Information Systems (Green IS). She had attended the original workshop as a coursework masters student and so was familiar with the Carbon Wiki project. The objective of her study was to examine the outcomes of the group projects of all the computer science students, identifying achievements and gaps in order to bring the project to the best possible conclusion. Taking a holistic, informing science perspective, this paper presents the outcomes of, and lessons learned from, this Green IS study which was completed in 2016.

Three research questions for the fifth phase of the project are as follows:

RQ1. Which business activities of small businesses in different industries are likely to have a significant environmental footprint?

RQ2. How can an online application be designed and implemented at low cost for the managers of small businesses to easily identify and track the environmental footprint of their business's activities?

RQ3 What can be learnt from this project about DSR when designing low-cost information systems for the public good?

It should be noted that the project had already started before the research described in this paper began as a Green IS investigation, using a DSR approach to the problem of creating at low cost information system as a repository of estimates of the environmental footprint of the activities of small business in different industries and circumstances. The understanding of DSR was based on the Orlikowski and Iacono (2001, as cited in Venable et al., 2012) view that the design of systems, data structures, and interfaces are legitimate IS artifacts as is the design of an artifact itself (Venable et al., 2012). The aim of the DSR approach is to create new knowledge through the design of IS artifacts, and the contribution of the research comes from what is learned through the design process, in this case when creating an information system for the common good with freely available software platforms with volunteers and student groups as labor. In the first year of the research, 2010, an extensive literature review was conducted, a summary of which is presented in the Background Section of the paper. The IS research student and her supervisors also attended the monthly project meetings where local business managers informed them of business activities that were likely to have a substantial environmental foot print. In subsequent years (2010-2012), the computer science student groups produced reports which documented the development of Carbon Wiki as a technical and informational artifact.

\section{DESIGN SCIENCE RESEARCH}

The computer science students and researchers, who had identified five technical phases involved in building and testing digital artifacts, had already developed the core of the artifact before the DSR perspective was clarified by the IS researchers. When the IS researcher student and her supervisors became involved, they recommended that a traditional linear DSR approach be adopted as this was consistent with the linearity of the five technical construction phases planned at the workshop and subsequent meetings.

The DSR steps followed are those recommended by Peffers et al. (2007) (see Figure 1). However, the computer science participants ignored the validation of the artifact in the Evolution of Theory and Reflection Step that would be critical for an IS DSR researcher (see Kuechler \& Vaishnavi 2011). 


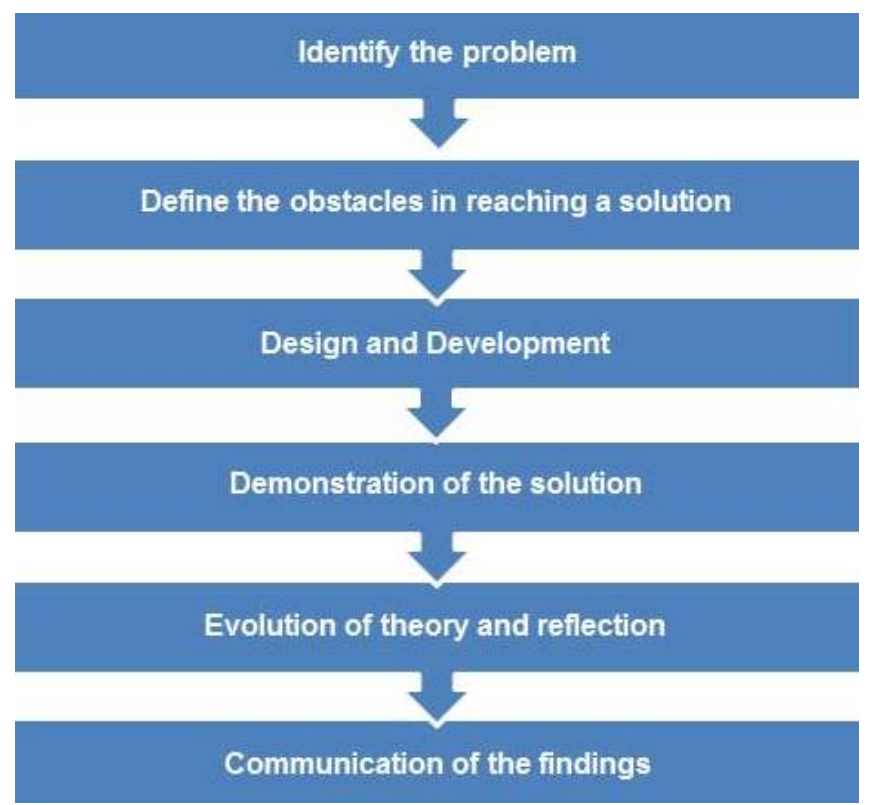

Figure 1. The Linear Steps of Design Science Research (Peffers et al., 2007)

Having conducted a literature review and an assessment of the progress of the project in the first two years, the IS researchers applied the steps of DSR framework in 2012 as follows:

Identify the problem: As described above, the multi-disciplinary team at the 2008 workshop initiated the Carbon Wiki project having identified that small businesses wanted to reduce their detrimental impact on the environment but lacked the tools to do so. Participants from small businesses requested an easy-to-use, free online application to enable them to identify and track the environmental footprint of their business activities. In 2010, the IS researchers reinterpreted the project through a constructivist approach, where computer science student teams created a suitable artifact, being the first three steps of this DSR framework in Figure 1. The research perspective interpreted the notion of activity through lens of activity theory, adding elements of evaluation and reflection as steps 4 and 5 in Figure 1.

Define the obstacles in reaching a solution: The anticipated obstacles recorded at the initial workshop were (1) to ensure relevance to businesses activities in different industries; (2) to ensure ease-of-use; (3) to focus on business activities, which pollute, not on things; and (4) to keep development costs to zero due to lack of funding and the limited circumstances of small businesses. It was necessary to rely on freely available applications, volunteer or student workers, and crowdsourced content. As describe in the paper, these anticipated obstacles were addressed by the ongoing involvement of the multidisciplinary team. However, a major obstacle emerged when the IS research student examined the Carbon Wiki produced by the computer science undergraduate students and found that they had not set up suitable data structures in the Carbon Wiki and its input forms. This indicated a deficiency in communication and a divergence of culture between student assignments and business user requirements. The implications of this are discussed below.

Design and Development: The elements of the artifacts that the IS DSR researchers identified for development are shown in Table 2.

It was assumed that Item 2 in Table 2 had been completed at the original workshop and follow up meetings, although the document seemed to have been lost, meaning that students had not given any heed to realistic business activities. The intention was that Items 1, 3, 4, 5, 6 and 7 would be under- 
taken by computer science student groups. An assessment of progress in 2012 revealed that only Item 1 had been satisfactorily completed.

\begin{tabular}{|ll|}
\hline \multicolumn{1}{|c|}{ Table 2: Artifact elements designed and/or created } \\
\hline 1. & the Carbon Wiki; - successfully installed before the IS research began \\
\hline 2. & a list of polluting activities of businesses in different industries; \\
\hline $\begin{array}{l}\text { 3. } \\
\text { forms for data entry created }\end{array}$ \\
\hline $4 . \quad$ wiki content by crowdsourcing; \\
\hline 5. & screen designs for the dashboard interfaces; \\
\hline 6. & navigation diagrams for patters of use; and \\
\hline 7. & the end-user dashboard for small businesses. \\
\hline
\end{tabular}

Demonstration of the solution: Some of the Items listed in Table 2 were presented at monthly meetings of the university team when the local business participants in the project were available. Early in 2012, the report from the student group who had developed the data structures and input form was released and we saw the first demonstration of the Carbon Wiki with forms to input data. This identified the shortcomings of these forms which simply allowed the contributor to describe their circumstances and estimate of the environmental footprint of their business activity as free text. For example, they could say something like "heating my office emits an estimated 50 carbon dioxide equivalents $\left(\mathrm{CO}_{2} \mathrm{e}\right)$ per month". However, the next group of computer science continued to carry out item 4 of the project to populate this version of the Carbon Wiki using these forms through pseudo-crowdsourcing (i.e., test entries from student and friends).

To reassess requirements for Item 2 in Table 2, the IS student researcher met with the project participants from business and scanned their website to draw up a new list of polluting activities and a minimum set data set for each. With assistance from one of the local IT consultants, a new set of data items and input forms were redesigned and re-implemented (see Figure 2). A report on this obstacle, and its implications for the linear DSR framework, was presented at an IS conference and received positive acceptance from IS scholars attending the session presented by the authors. Feedback was received from these presentations and the DSR framework redesigned to incorporate a feedback loop (see Figure 4).

Once the new forms were implemented in the Carbon Wiki, the wiki content was reentered to give some meaningful text content. Items 5 and 6 from Table 2 were subsequently undertaken by the IS researchers and evaluated by the project participants at monthly meetings until the business participants approved the designs (an ex ante design evaluation as described in the literature (Venable et al., 2012)). Item 7 is yet to be done.

Evolution of Theory and Reflection: At this step, the authors were influenced by two concepts that promote and explain the role of researchers in drawing inferences from practical experience in their field of expertise. The first concept is that of the reflective practitioner (Schön, 1991) which focusses on the relationship of reflection-in-action within professional activity. Schön (1991) argues that social systems can learn to become capable of transforming themselves without intolerable disruption through the interpretations of investigations of phenomena by experts. The second concept is that of the engaged scholar (Van de Ven, 2007) which is a participative form of research for obtaining the views of key stakeholders to understand a complex problem. It can also be used to place the academic resources of a university to work in solving pressing public problems and thereby contributing 
to the public good. The results of this reflection are presented in the Discussion Section of the paper.

Communication of findings: This paper is the communication of the findings.

\section{DESIGN OUTCOMES}

The contributions of the IS DSR researcher perspectives include (1) the use of the activity theory lens in identifying business activities; (2) the redesign of the data structures and input forms; and (3) the importance of designing the output screens and end-user navigation as well as evaluating those designs before implementation. These contributions are each discussed here.

\section{IDENTIFICATION OF BUSINESS ACTIVITIES}

According to activity theory, activities are purposeful things that people do with the use of appropriate tools. Business activities are carried out by managers and workers for specific purposes in their operations. Activity theory advises that better outcomes come from a focus on the activity not the tool. We use the example of space heating and cooling where the objective is to keep space, such as an office, at the right temperature whatever tool is used. In developing the input forms, we held discussion to label each with the name of the activity not the tool, e.g., "heating the office" not "using the heater".

On advice from participants at the original multi-disciplinary workshop, lists were recreated of typical polluting activities specific to businesses in different industries. This began with two basic lists, one for manufacturing and one for service industries. Typical activities were found in discussion with business managers who came to ongoing project meetings and by studying websites of suitable business and the list customized and expanded where necessary (see Ionescu, 2015). Activities were chosen that were not only common activities of that business, but they are also activities that would potentially contribute significantly to the environmental footprint of the businesses. The lists were shown to people familiar with these businesses to verify that the activities most likely to have a significant environmental impact were identified. The basic data items for each activity were also identified to help structure input forms of the Carbon Wiki and, later on, the dashboard interface for each type of business.

\section{RESTRUCTURING THE WIKI KNOWLEDGE REPOSITORY}

The computer science students were successful in installing the open source wiki on the university server in 2010. However, when they demonstrated the wiki, it was clear that the mechanism for data collection was inadequate in the light of the systems analysis of Phase 5. They had created only one generic input form and the only explicit numerical data item was an emissions estimate for an activity in Carbon dioxide equivalents $\left(\mathrm{CO}_{2} \mathrm{e}\right)$. Everything else was free-form text. For example, if someone gave an estimate of the environmental footprint of heating their office in winter, there was nowhere on the form to input other essential data items such as the size of the office, the number of degrees of heating, and time frame on which their estimate was based. Even if this data was mentioned in the free-form text there was often no indication of what measurements units were used. This made implementation of data in the widgets in the dashboard impossible. Every data record would have one variable in carbon dioxide equivalents $\left(\mathrm{CO}_{2} \mathrm{e}\right)$ but different other variables depending on the activity (e.g., the space heating activity form has variables that include volume, time, and temperature).

As a substantial component of the research, a new set of forms were designed and implemented in the Carbon Wiki. Figure 2 is presented as an example for space heating. Other activities were running office, transporting, water heating, procurement, running data center, cooking, room cleaning, catering, etc. 


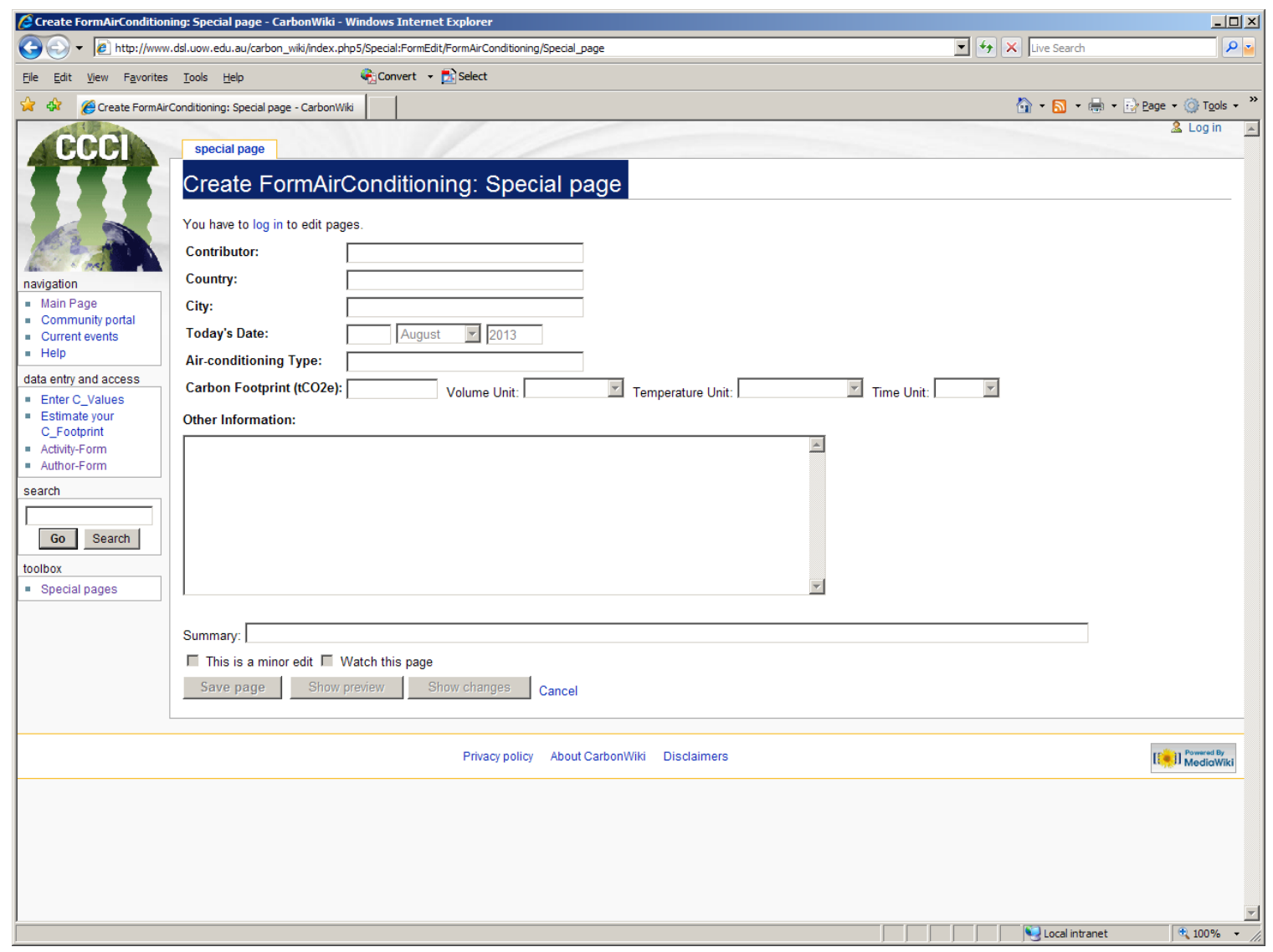

Figure 2. A wiki form used to collect data on cooling/heating spaces. The user must enter a value of $\mathrm{CO}_{2} \mathrm{e}$ for a given volume, for a specific temperature rise and for a specified time.

\section{SCENARIOS OF USE OF THE DASHBOARD/DASHBOARD NAVIGATION}

The end-user interface to the wiki for small businesses is a succession of screens that the users will navigate in order to obtain the calculation of $\mathrm{CO}_{2}$ emissions for the appropriate activities in their business. A basic representation of these screens is represented in Figure 3 leading up to Screen 6 which takes the form of a widget-based, interactive dashboard such as the Microsoft's Digital Dashboard Toolkit (Digital Dashboard Toolkit (Nguyen, 1999) where the environmental footprint of all activities are displayed and opportunities to reduce them can be interactively explored.

A typical scenario from the hospitality industry comes from a small takeaway business where the manager decides to use the dashboard in order to calculate the environmental footprint of its business activities. He/she will follow the instructions displayed on the ordered screens. At Screen No.3 one activity can be chosen at a time, for instance heating or cooling the premises, and then he/she will choose the most appropriate entry from the wiki repository. After that step, the variables, e.g., volume of the room, temperature range, and duration of heating/cooling, are entered and the calculation of $\mathrm{CO}_{2} \mathrm{e}$ is made. 


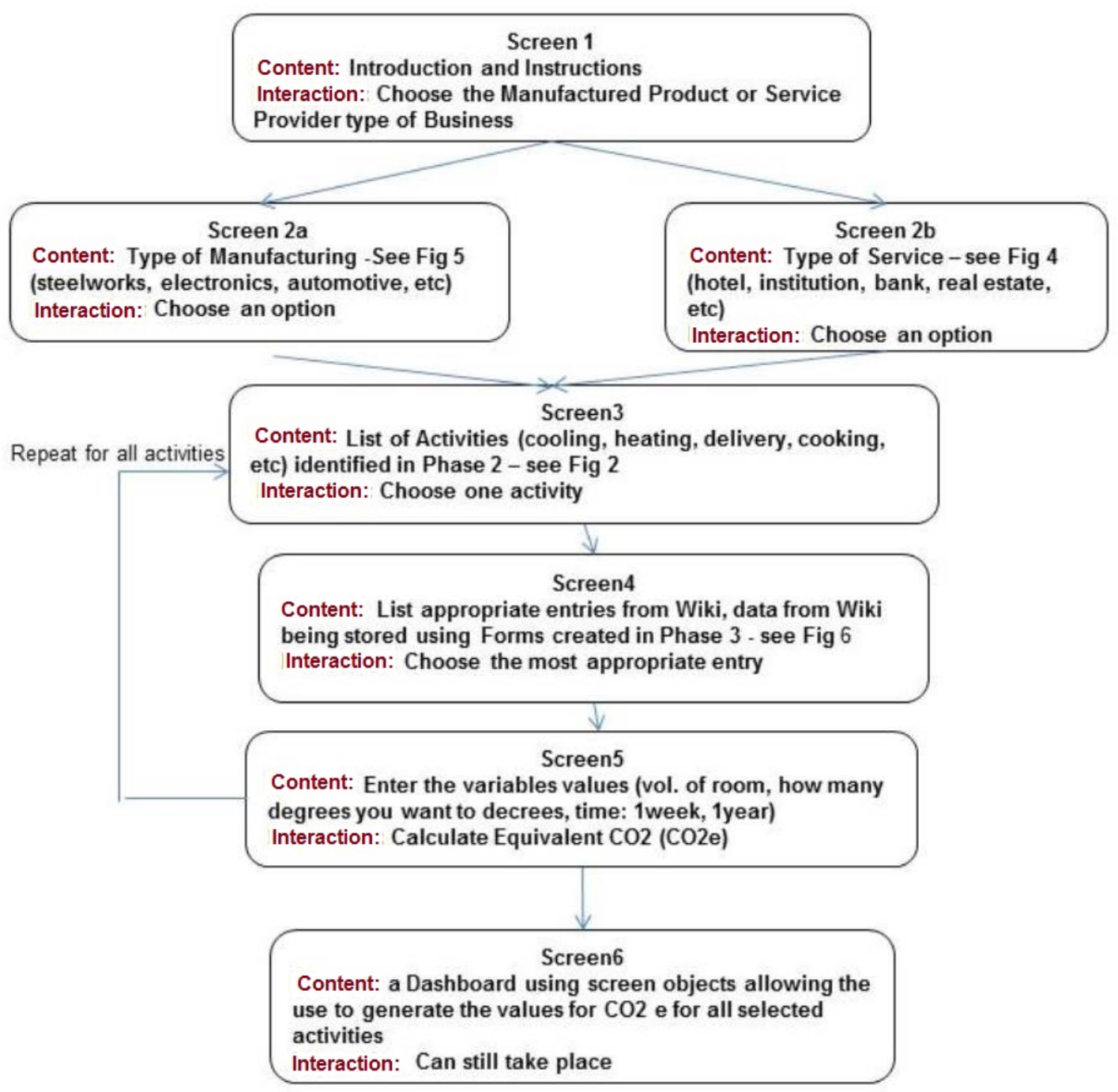

Figure 3. An outline of the Navigation though the dashboard interface to the Carbon Wiki

Further screen design would then depend on the widgets (slide bars, graphs, etc.) in whatever freely available tool was chosen by the computer science student team implementing the dashboard. Thus the outcomes of the research as presented in this paper would inform a revision of the work of a new group of computer science students.

\section{ANSWERING THE RESEARCH QUESTIONS}

The research questions were answered in the following way:

RQ1. Business activities were identified that were both common activities of the businesses in specific industries and have a significant environmental footprint. Lists of these activities were generated for typical businesses in across different industries. These activities were authenticated through meetings with small business managers and studying websites of small businesses representing different industries. The lists provided the basis on the structure of data to be collected and stored in the Carbon Wiki as well as how the screens of the dashboard would be designed. The emphasis on defining an activity by its purpose was due the application of activity theory. 
RQ2. The project demonstrated that a low-cost, easy to use system can be created by a team of highly motivated team for a significant social issue. The influence of the research on the outcomes of the project were:

- the redesign of the open source wiki;

- identification of polluting business activities; design and redesign of data for the wiki input forms;

- the design of the dashboard interface; and

- a navigation process through which end-users could access relevant information to estimate their environmental footprint.

RQ3. Research Question 3 concerns what can be learnt from this project. In this regard, the IS DSR research adds the DSR framework of Figure 1 with particular learnings from the fourth and fifth step of the DSR process, namely the activities of evaluation, evolution of theory and reflection. As described above, the team-working on this project included both reflective practitioners (Schön, 1991) and engaged scholars (Van de Ven, 2007). The reflections of the IS practitioners and engaged IS scholars are presented in the following discussion.

\section{DISCUSSION}

It was first thought that our biggest challenge would be to build a useful and sustainable information system with no budget or fixed resources. The academic, practitioner, and student participants in the project were avid environmentalists who were keen to provide time and expertise to the project and to cooperate across traditional discipline boundaries. The process of designing and implementing the open source Carbon Wiki went ahead with the first groups of computer science students mentored by a local computer company. The first lesson learnt was that the goodwill and passion that are usually associated with teams working on projects for the common good can overcome obstacles in associated with a lack of funding and resources. In particular with IS projects, we noted that there is ample open source software available and volunteer students are willing to implement such systems. Our literature review had alerted us to potential communication and coordination challenges in projects involving diverse groups of volunteers working across different cultures (Van Gorp, 2014). We detected significant, but not unexpected, differences in culture and motivation between researchers, student, and small business people. Students, in particular, were primarily focused on finishing their allotted task by the due date, getting a good grade, and moving on. They also had little teamwork experience and spent more time sorting out who was doing what than actually working on the task. Their reports contained minimal information that was useful for subsequent student groups and tended to conceal any problems that should be known but that might lower their grade. The assumption made by business people at the original workshop was that each group of students working on their phase of the project would be aware of, and contact, the students in other groups. As the project was spread over different semesters, courses, and schools which were widely dispersed on the university campus, communication between the groups was minimal and thus a source of problems identified in the IS DSR research.

It was assumed that subsequent activities of crowdsourcing the content and developing an easy-touse, graphical user interface (GUI) dashboard interface for small businesses would also be a straight forward process. However, problems can arise when different system building activities are undertaken by independent groups with different perspectives on systems development. This can occur when in voluntary projects. Our particular problem was the different interpretations of the data structures in the wiki between the technology focused computer scientists and the business focus of IS researchers.

Our reflection on this contradiction tells us that the groups who built the wiki regarded a successful outcome of their activity was a working system, namely the Carbon Wiki. To them the purpose of the activity of downloading and installing the MediaWiki engine on the Computer Science Department's 
server was to get it to work, which they did very well. Success to them meant that the wiki was publically available with a single generic form to enable people anywhere to enter data. How the data would be used on the dashboard was not a consideration.

The discipline of IS brings a different perspective on success and is concerned with the whole systems lifecycle where the development of the system is only a stage in a process that included gathering user requirements, designing data structures and flows, the input and processing of data, and the designing of end-user interfaces that meet the user specifications and are easy to implement. In our case, structuring the data was important, as end-users would have great difficulty in deducing meaningful and relevant information if users had to search through thousands of wiki entries to find some relevant data that they could apply to their business. With some basic structure to the data, the system could be enhanced to do much of the work for them. We used the example of space heating/cooling to demonstrate the system. Once selecting that activity, all relevant entries in the wiki could be displayed so that users scan the text that gave information about the type of heating or cooling and choose the most relevant entry. Users could then enter their room volume, desired temperature rise, and time period. The system could then automatically calculate their estimated emissions for them. Indeed, the whole idea of a dashboard is to provide this type of functionality. The IS researchers had assumed that this was obvious to other team members and there was a delay in the project when the IS student had to redesign the forms and acquire the expertise to implement them.

We noted that our experience would not be unique in this type of project and so we present Figure 4 as a more general framework that adds feedback steps to the traditional linear DSR steps depicted in Figure 1.

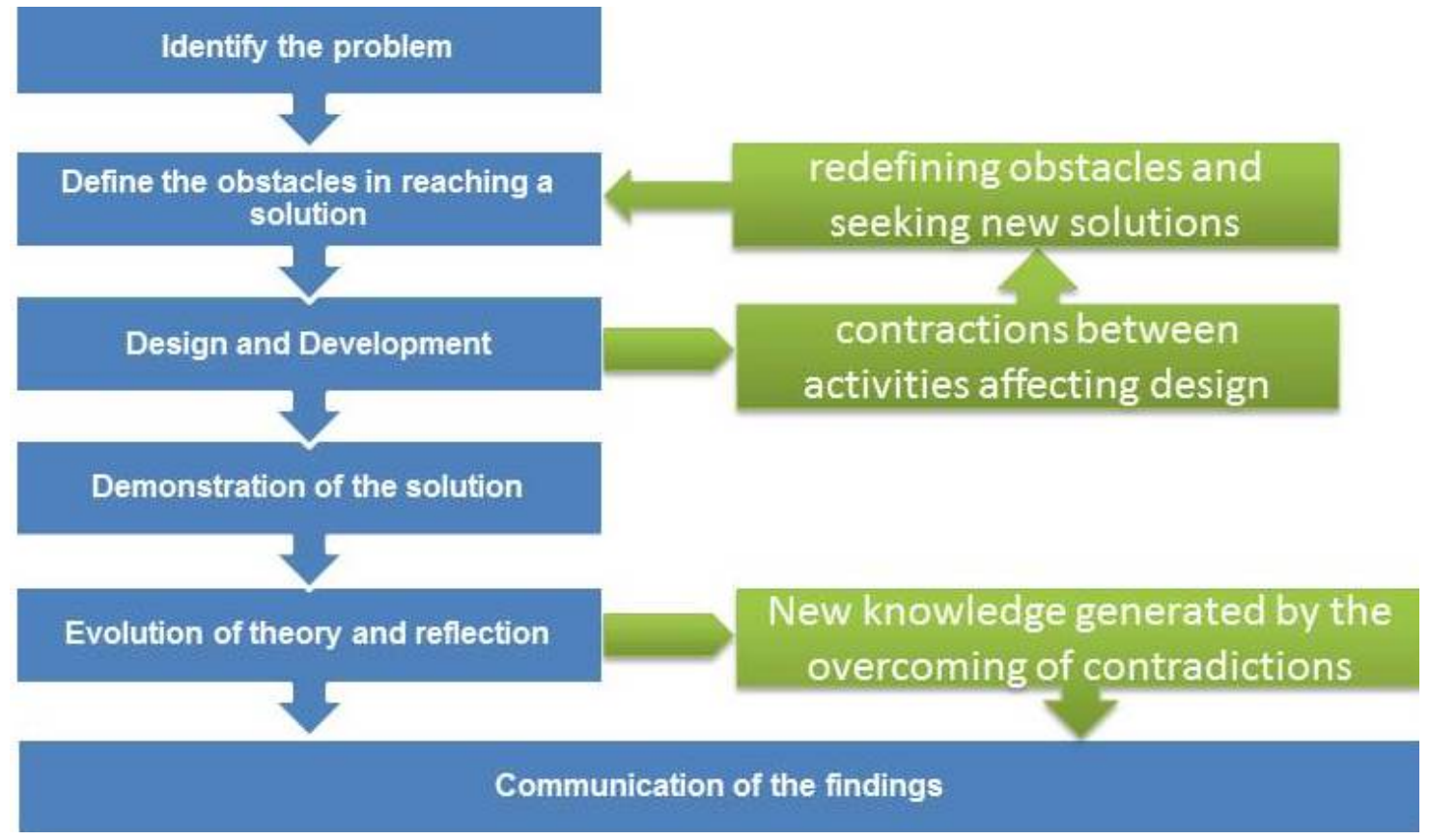

Figure 4 The implications for the traditional DSR process shown in Figure 1 when major unexpected obstacles occur during the Design and Development step

This project represented a more complex and iterative process than a linear DSR framework allows, incorporating contradictions between the activities of the different participants. As previously mentioned, learning through the processes of resolving contractions is a phenomenon well understood by activity theorists (Engeström, 1987). From an activity theory perspective, the contradictions between the activities of the computer science developers and the activities of end-user in small business are frequently encountered by IS scholars. IS scholars are familiar with an approach to systems development that begins with a requirements gathering stage where the need of end-users are documented 
and analyzed. These are not always appreciated by students of computing science courses (Kuechler \& Vaishnavi, 2011).

Methodologies traditionally used by IS practitioners include structured systems analysis and design and the system development life cycle (Curtis \& Cobham, 2005). IS systems developers are also familiar with tools, such as entity relationship diagrams, which deal with data structures, and data flow diagrams, which focus on data processes (Curtis \& Cobham, 2005). More recently data structures and processes come together in agile object-oriented approaches to design. In dashboard interfaces, web-enabled screen objects have brought a new approach to IS data structures making them invisible to the end-user developer. However, good structure is still essential to underpin such easy-to-use interfaces. Applications, such as the wiki and dashboard, reinforce in the way modern technology is evolving. However, the findings of this study show that, while these end-user tools suit straight-forward problems, the fundamental knowledge of IS professionals is required when it comes to the data and processes of more complicated applications (Kuechler \& Vaishnavi, 2011).

After revising the linear DSR framework of Figure 1, which we originally used to frame the DSR approach to our study, we revisited the literature and found the DSR framework depicted in Figure 5, concerning the IS approach to DSR (Kuechler \& Vaishnavi, 2011). Although our study differs from the studies used to develop this framework in timescale and intent, we believe that our study affirms the findings of Kuechler and Vaishnavi (2011) on the unique perspectives that informing science and information systems scholars bring to DSR, providing a platform to apply DSR to more complex problems.

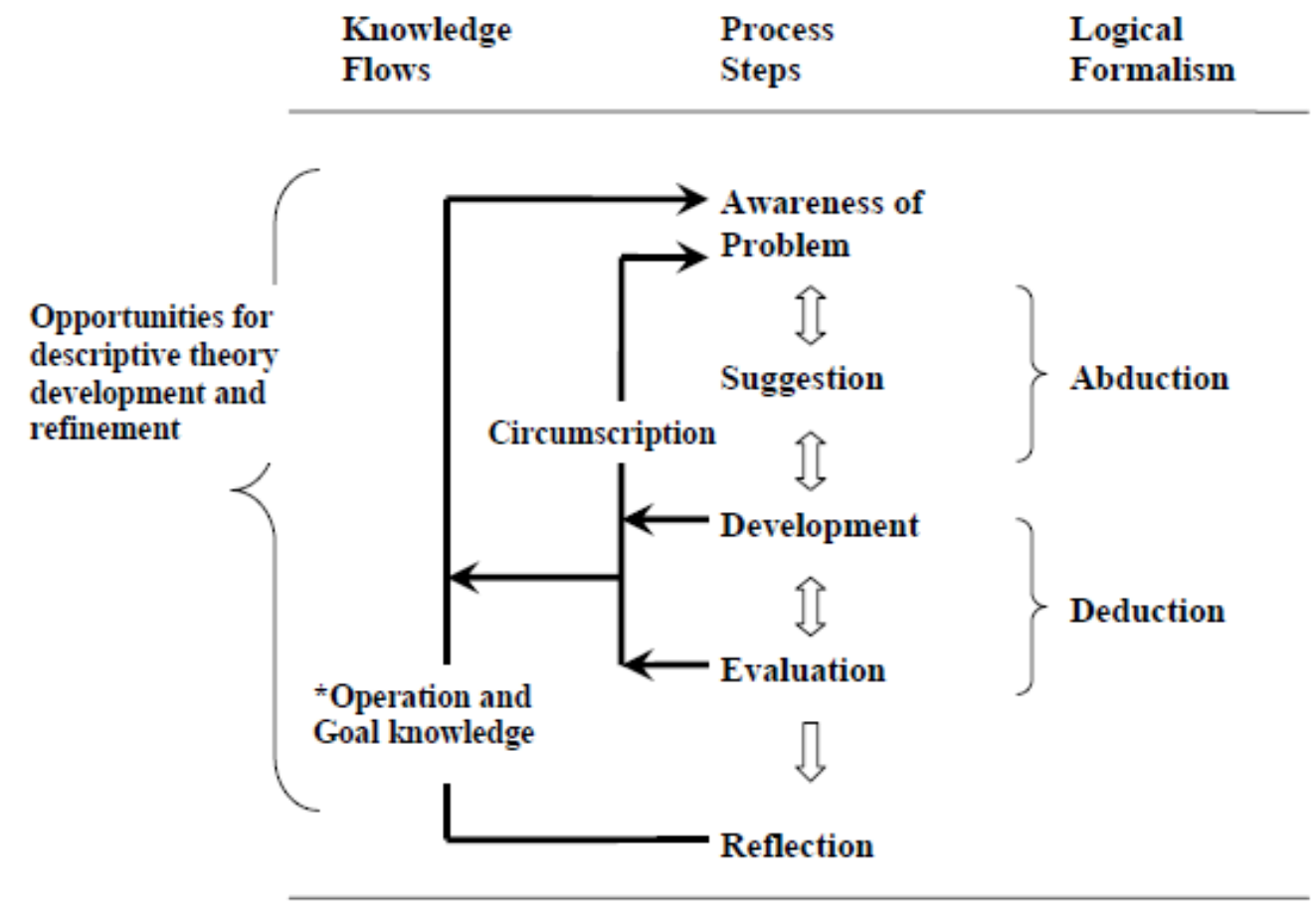

Figure 5. The IS DSR Framework of Kuechler and Vaishnavi (2011)

One final issue on which we wish to reflect is that, in accord with Venable et al. (2012), the design of a new system can its self be an artifact that can be evaluated as an outcome of a DSR study. In our case, the design of the dashboard user interface and navigational structure concluded our input into the Carbon Wiki project and thus concluded our study. These design artifacts were co-created with the end-users, whose signoff indicated that they had evaluated them and deemed them to be satisfactory for implementation. Indeed, it was evident that the small business managers had learned a great 
deal about the environmental footprint of their business activities through their involvement in the dashboard screens and navigation, even without access to the intended content of a completed Carbon Wiki.

\section{CONCLUSION}

This research contributes to the fields of Green IS and Informing Science by presenting the results of a study of a climate change mitigation project which had both successes and challenges over a period of seven years. The findings of the study demonstrate the viability of a freely-available easyto-use online system for small businesses to estimate and track the environmental footprint of their business activities. It is envisaged that this will further enable small businesses to redesign the way they do business to be more environmentally responsible.

The developed system is novel as its intended end-users are owners and managers of small businesses who intend to be environmentally responsible but do not have the resources that a large organization would have to do this. The project uses publicly available applications and student resources as labor. It is unique in focusing on activities rather than things such as appliances and relies on the holistic notion of activity from activity theory to support this approach.

The study of the project conducted by IS scholars adopted a DSR approach to creating new knowledge through the design of ICT artifacts. The limitations of a linear DSR process were discovered during the study, when requirements for the end-user dashboard were about to be drawn up towards the end of the project. This revealed contradictions between these requirements and the input data forms which were the early technical focus of computer science students in implementing the Carbon Wiki. We suggest that these types of contradictions would occur in similar resource poor, collaborative projects undertaken by students and environmental advocates. The case presented here suggests that more complex DSR frameworks are needed for the investigation of complex systems for small businesses.

\section{REFERENCES}

Aldy, J. E., Krupnick, A. J., Newell, R. G., Parry, I. W. H. \&, Pizer, W. A. (2010). Designing climate mitigation policy. Journal of Economic Literature, 48(4), 903-934.

Australian Government. (2007). National Greenbouse and Energy Reporting Act 2007. Accessed May 28, 2015 from http://www.comlaw.gov.au/Series/C2007A00175

Avison, D., \& Elliot, S. (2006). Scoping the discipline of information systems. In J. L. King \& K. Lyytinen (Eds.), Information systems: The state of the field (pp. 3-18). Chichester, England: John Wiley \& Sons.

Avital, M., Lyytinen, K. J., King, J. L., Gordon, M. D., Granger-Happ, E., Mason, R. O., \& Watson, R. T. (2007). Leveraging information technology to support agents of world benefit. Communications of the Association for Information Systems, 19(1), 25.

Baskerville, R. L., \& Myers, M. D. (2002). Information systems as a reference discipline. MIS Quarterly, 26(1), 114.

Bos-Brouwers, H. (2010). Corporate sustainability and innovation in SMEs: Evidence of themes and activities in practice. Business Strategy and the Environment, 19(7), 417-435.

Bramwell, A., \& Wolfe, D. A. (2008). Universities and regional economic development: The entrepreneurial University of Waterloo. Research Policy, 37(8), 1175-1187.

CFO. (2009). The next wave of green IT: IT's role in the future of enterprise sustainability. Retrieved on 29 January 2009 from www.CFO.com

Chali, J. (2013). Corporate social responsibility in supply chains: Current state and research direction. International Journal of Business, Management \& Social Science, III(2), 1-8. 
Wiki for Tracking the Environmental Footprint

Chen, A. J. W., Boudreau, M., \& Watson, R. T. (2008). Information systems and ecological sustainability. Journal of Systems and Information Technology, Sustainability and Information Systems, 10(3), 186-201.

Coghlan, D., \& Brannick, T. (2014). Doing action research in your own organization. Sage.

Cohen, E. B. (2009). A philosophy of informing science. Informing Science: the International Journal of an Emerging Transdiscipline, 12, 1-15. Retrieved from https://www.informingscience.org/Publications/425

Curtis, G., \& Cobham, D. (2005). Business information systems analysis, design and practice. Edinburgh Gate, Harlow, UK: Person Education Limited.

Drechsler, A. (2015). Designing to inform: Toward conceptualizing practitioner audiences for socio-technical artifacts in design science research in the information systems discipline. Informing Science: the International Journal of an Emerging Transdiscipline, 18, 31-45. Retrieved from https://www.informingscience.org/Publications/2288

Elliot, S. (2011). Transdisciplinary perspectives on environmental sustainability: A resource base and framework for IT-enabled business transformation. MIS Quarterly, 35(1), 197-236.

Engeström, Y. (1987). Learning by expanding, Helsinki: Orienta Konsultit.

Fuchs-Kittowsk, E., \& Köhler, A. (2002). Knowledge creating communities in the context of work processes. ACM SIGCSE Bulletin, 3, 8 - 13.

Gregor, S. \& Hevner, A. R. (2013). Position and presenting design science: Research for maximum impact. MIS Quarterly. 37(2), 337-355.

Guo, W. (2004). Guiding students learning project team management from their own practice. Issues in Informing Science and Information Technology, 1, 267-277.

Hasan, H., \& Pfaff, C. (2006). The Wiki: An environment to revolutionise employees' interaction with corporate knowledge. Proceedings of OZCHI Design: Activities, Artefacts and Environments, pp. 377-380.

Hasan, H., Smith, S., \& Finnegan, P. (2017). An activity theoretic analysis of the mediating role of information systems in tackling climate change adaptation. Information Systems Journal, 27(3), 271-308.

Hevner, A. R., March, S.T., Park, J., \& Ram, S. (2004). Design science in information systems research. MIS Quarterly, 28(1), 75-105.

Howard, G. R., Lubbe, S., \& Klopper, R. (2015) Green IS: Enabling, transforming, both, or neither? Proceedings of Informing Science \& IT Education Conference (InSITE) 2015, pp. 231-245. Retrieved from http://proceedings.informingscience.org/InSITE2015/InSITE15p231-245Howard1521.pdf

Ionescu, C. (2015). Tracking the environmental footprint of business activities. Master of Philosophy thesis, Sydney Business School, University of Wollongong, 2015. Retrieved from http://ro.uow.edu.au/theses/4651

Kock, N. F., Jr., McQueen, R. J., \& John, L. S. (1997). Can action research be made more rigorous in a positivist sense? The contribution of an iterative approach. Journal of Systems and Information Technology, 1(1), 1-23.

Kuechler, B., \& Vaishnavi, V. (2011). Promoting relevance in IS research: An informing system for design science research. Informing Science: The International Journal of an Emerging Transdiscipline, 14, 125-138. Retrieved from https://www.informingscience.org/Publications/1498

Kuutti, K. (1995). Activity theory as a potential framework for human-computer interaction research. In B. Nardi (Ed.), Context and consciousness: Activity theory and buman-computer interaction (pp. 17-44). Cambridge, MA: MIT Press.

Leontiev, A.N. (1981) Problems of the development of mind. Moscow: Progress Publishers.

Majchrzak A., \& Malhotra A. (2013). Towards an information systems perspective and research agenda on crowdsourcing for innovation. Journal of Strategic IS, 22, 257-268.

Malhotra, A., Melville, N. P., \& Watson, R. T. (2013). Spurring impactful research on information systems for environmental sustainability. MIS Quarterly, 37(4), 1265-1274. 
Mauser, W., Klepper, G., Rice, M., Schmalzbauer, B. S., Hackmann, H., Leemans, R., \& Moore, H. (2013). Transdisciplinary global change research: The co-creation of knowledge for sustainability. Current Opinion in Environmental Sustainability, 5(3), 420-431.

McKay, J., \& Marshall, P. (2001). The dual imperatives of action research. Information Technology \& People, 14(1), 46-59.

Meloche, J. A., Hasan, H. M., Willis, D., Pfaff, C., \& Qi, Y. (2009). Co-creating corporate knowledge with a Wiki. International Journal of Knowledge Management, 5(2), 33-50.

Melville, N. (2010). IS innovation for environmental sustainability. MIS Quarterly, 34(1), 1-21.

Molla, A., Cooper, V. A., Corbitt, B., Deng, H., Peszynski, K., Pittayachawan, S., \& Teoh, S. (2008). E-readiness to G-readiness: Defining (developing) a green information technology readiness framework. 19th Australasian Conference on IS, Christchurch, 669-678.

Muller, C. L., Chapman, L., Johnston, S., Kidd, C., Illingworth, S., Foody, G., ... Leigh, R. R. (2015). Crowdsourcing for climate and atmospheric sciences: Current status and future potential. International Journal of Climatology, 35(11), 3185-3203

Nguyen, C. T. (1999) Build your own dashboard. Retrieved from http://windowsitpro.com/windows/build-yourown-digital-dashboard

Onojaefe, D., \& Leaning, M. (2007). The importance of partnerships: The relationship between small businesses, ICT and local communities. Issues in Informing Science and Information Technology, 4, 725-735. Retrieved from https://www.informingscience.org/Publications/983

Pachauri, R. K., \& Reisinger, A. (Eds.). (2007). Climate change 2007: Synthesis report. Contribution of Working Groups I, II and III to the Fourth Assessment Report of the Intergovernmental Panel on Climate Change, IPCC, Geneva.

Peffers, K., Tuunanen, T., Rothenberger, M. A., \& Chatterjee, S. (2007). A design science research methodology for information systems research. Journal of MIS, 24(3), 45-77.

Philipson, G. (2010). The energy consumption and carbon footprint of ICT usage in Australia in 2010. Retrieved from http://www.acs.org.au/attachments/ICFACSV4100412.pdf

PytlikZillig, L. M., \& Tomkins, A. J. (2011). Public engagement for informing science and technology policy: What do we know, what do we need to know, and how will we get there?. Review of Policy Research, 28(2), 197-217.

Regolini, A., Berger, F., Jannès-Ober, E., \& Dorren, L. (2008). From tailored databases to Wikis: Using emerging technologies to work together more efficiently. Interdisciplinary Journal of Information, Knowledge and Management, 3, 103-113. Retrieved from https://www.informingscience.org/Publications/93

Rowsell-Jones A. \& Mingay S. (2008). Going green: The CIO's role in enterprise wide environmental sustainability. Gartner EXP premier, May.

Schön, D. A. (1991). The reflective practitioner: How professionals think in action. Aldershot, UK, Arena Ashgate Publishing.

Seidel, S., Recker, J., \& vom Brocke, J., (2013). Sensemaking and sustainable practicing functional affordances of information systems in green transformations. MIS Quarterly, 37(4), 1275-1299.

Singh, G., Hawkins, L., \& Whymark, G. (2007). An integrated model of collaborative knowledge building. Interdisciplinary Journal of E-Learning and Learning Objects, 3(1), 85-105. Retrieved from https://www.informingscience.org/Publications/388

Storer, J., Chao, J., Torelli, A., \& Ostrowski, A. (2016). KnoWare: A system for citizen -based environmental monitoring. Informing Science: the International Journal of an Emerging Transdiscipline, 19, 125-139. Retrieved from https://www.informingscience.org/Publications/3500

Tekin, E. K., Ertürk, A., \& Tozan, H. (2015). Corporate social responsibility in supply chains. In H. Tozan \& A. Erturk (Eds.), Applications of contemporary management approaches in supply chains. InTech.

Van de Ven, A. H. (2007). Engaged scholarship: A guide for organizational and social research. Oxford University Press. 
Wiki for Tracking the Environmental Footprint

Van Gorp, A. (2014). Integration of volunteer and technical communities into the humanitarian aid sector. In Barriers to Collaboration Proceedings of the Information Systems for Crisis Response and Management Conference (ISCRAM 2014).

Venable, J., Pries-Heje, J., \& Baskerville, R. (2012). A comprehensive framework for evaluation in design science research. In International Conference on Design Science Research in Information Systems (pp. 423-438). Springer, Berlin, Heidelberg.

Vygotsky, S. (1978) Mind and society. Cambridge, MA: Harvard University Press.

Walls, J. G., Widmeyer, G. R., \& El Sawy, O. A. (1992). Building an information system design theory for vigilant EIS. Information Systems Research, 3(1), 36-59.

Walsham G. (2012). Are we making a better world with ICTs? Reflections on a future agenda for the IS field. Journal of Information Technology 27, 87-93

Waterman, H., Tillen, D., Dickson, R., \& De Koning, K. (2001). Action research: A systematic review and guidance for assessment. Health Technology Assessment, 5(23)

Watson, R. T. (2007). Leveraging information technology to support agents of world benefit. Communications of the AIS, 19, 567-588.

Watson, R. T., Boudreau, M. C., \& Chen, A. J. W. (2010). Information systems and environmentally sustainable development: energy informatics and new directions for the IS community. MIS Quarterly, 34(1), 23-38.

Wood-Harper, A. T. (2011). Characteristics of information systems definition approaches. In R. L. Flood, M. C. Jackson, \& P. Keys (Eds.), Systems prospects (pp. 359-367). U.S.: Springer.

World Commission on Environment and Development. (1987). Report of the World Commission on Environment and Development: Our Common Future. Retrieved from http://www.un-documents.net/our-common-future.pdf

\section{BIOGRAPHIES}

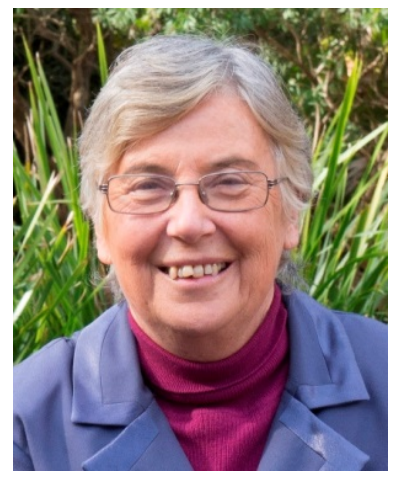

Helen Hasan is a Professor of Information Systems at the Australian Health Services Research Institute of the University of Wollongong. Using Complex and Activity Theories, Helen conducts research into wicked problems such as social use of IT by the elderly for improved wellbeing; Green IT for sustainable development; and social determinants of indigenous health. Helen has received University Awards for Research Student Supervision (2012), Interdisciplinary Research Excellence (2015) and Community Engagement (2017).

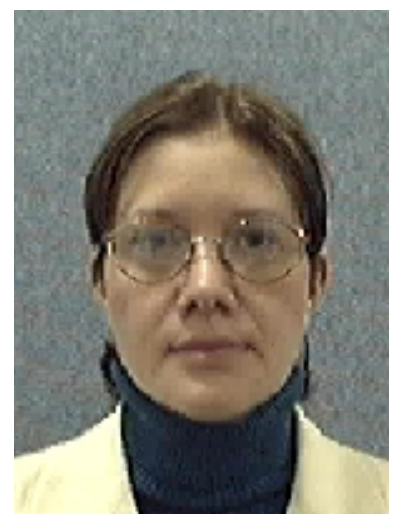

Corina Ionescu has a first degree in Environmental Science, a coursework Masters in Information Systems and a Master of Philosophy by Research. She has vast experiencing in teaching the basics of Information Systems and works as a tutor at the University of Wollongong. 